Ethiopian Journal of Environmental Studies \& Management 8(Suppl. 1): 799 - 809, 2015.

ISSN:1998-0507

doi: http://dx.doi.org/10.4314/ejesm.v8i1.7S

Submitted: June 07, 2015

Accepted: October 08, 2015

\title{
AN EMPIRICAL ANALYSIS OF THE EFFECT OF COMMERCIAL MOTORCYCLE RESTRICTION POLICY ON PUBLIC HEALTH AND SAFETY IN LAGOS STATE
}

\author{
*DINA, A.0., AKANNI, C.0., BADEJ0, B.A. AND ORUMA, M. \\ Department of Geography and Regional Planning, Olabisi Onabanjo University, Ago-Iwoye, \\ Ogun State
}

\begin{abstract}
The decision to enact laws which enforce the restriction of commercial motorcycle operation to the back streets of Lagos metropolis in 2012 has been greeted with mixed feeling. Motorcycle appearance within Nigeria's urban transport scene is fraught with many safety challenges which include use of drugs, over-speeding, overloading, non observance of traffic laws, non use of rear mirror and receiving calls while riding were identified as the major causes of accidents among operators. The costs associated with these accidents culminated in a wave of outright ban in several states in the country, however the Lagos State Government opted for restriction of their operations within the metropolis, the impact of the approach on security and safety has been hugely debated. This study made use of primary and secondary data in a survey of 120 commercial motorcyclists operating within Ikeja Local Government Area, the capital of Lagos State. Primary data was presented using descriptive method while the secondary data was analyzed using quadratic regression model from a scatter plot of 5 year monthly accident admission cases from a federal orthopedic hospital in Lagos. Results from the survey indicate a significant improvement in the security challenge posed by commercial motorcycle operations while the downward trend in the observed cases of motorcycle hospitalization from analysis is consistent with introduction of the law restricting their operations. Forecast using trend-cycle of the seasonal decomposed series indicates motorcycle accident admission cases will end within first 5 months of 2015. The study concludes enforcement of the law has made a huge positive impact and therefore should be sustained.
\end{abstract}

Key Words: Motorcycle Restriction Policy, Health and Safety, Lagos State

\section{Introduction}

The use of the motorcycle as a means of public transportation is a popular phenomenon across nations of the world especially in the low and middle income countries (WHO, 2004). In Nigeria, this para-transit contraption popularly called "Okada" initially emerged as a means of transportation within rural communities (Tijani, 2013). Nwaorgu; (2011) noted that "Okada" however found its way as a means

*Corresponding author: Dina, A.O.

Email: dinaolu@gmail.com of public transportation within the county's cities from late 80 's to early 90's.

Several reasons have been advanced for their emergence as an acceptable means of public transportation within Nigeria's urban and city landscape. These include Nigeria's economic depression in the early eighties led to massive unemployment (Ogunsanya and Galtima, 1993), decrease in the supply of new vehicles (Oyesiku, 2002), drop in the quantity and quality of 
public transport services, ease which "Okada" negotiates traffic congestion (Asekhame and Oisamoje, 2013), political patronage of operators, ease of access to the service (Oluwaseyi et al., 2014; Olusanya, 2011) and finally lack of an articulated transport policy structure to ensure sustainable development of transport infrastructure capacity (Badejo, 2011). Oluwaseyi et al. (2014) further opined that Lagos state status as a former federal capital, chief commercial and industrial city, chief port city, the most densely populated area in Nigeria and the economic power base of Nigeria culminated in emergence of commercial motorcycle operations in 1992.

Their rapid growth and prominence in the metropolis is therefore associated with the effort to cope with various mobility deficiency of public transportation particularly the endemic traffic gridlock, an insignia of Lagos. As at 1995, an estimated 450,000 motorcycles operated within the metropolis alone (Oluwaseyi et al., 2014).

However, the most important positive socio-economic impact of "Okada" in Nigeria is the provision of easy employment opportunity for the teeming number of unemployed youth, retirees and other quasi operators desirous of augmenting their regular source of income (Ogunrinola, 2011). The relative ease of acquiring and starting off a commercial motorcycle service altogether ensured a steady influx of migrant operators into Lagos metropolis from within and outside Nigeria. As laudable as the positive economic relevance of "Okada" operation is to employment generation, the near absence of their regulation in Lagos state, Nigeria also resulted in an unquantifiable social, economic, psychological and health cost to residents and government at the state or federal level.

The Lagos traffic law among others restrict the activities of "Okada" riders to about 60 back street roads throughout the state with attendant penalty for violators is a direct policy response to regress the health and safety risk of commercial motorcycle operation. The law is intended to protect the lives of both "Okada" riders and other road users against observed excesses of riders which culminate into high frequency of accidents, injuries and untimely deaths. This study examines how the law has fared on safety and security in Nigeria's chief commercial city of Lagos.

\section{Statement of Problem}

There are many negative behavioral excesses associated with commercial motorcycle operators that increase accident risk. These have been adequately captured in literature to include use of drugs, overspeeding, unlicensed and untrained motorcyclists, impatience, over loading, dangerous over-taking, non observance of traffic laws, non use of rear mirror and receiving calls while riding were the major causes of accidents among the commercial motorcyclists (Mburza and Umar, 2008; Oni, et al., 2012; Ogunmodede et al., 2012; Kranjcar, 2013). Further fallout of accidents as noted by the work of Boye (2013) is that injuries to limbs are the most common to riders accident while Eze et al. (2013) observed that skull fractures sustained posed the most serious threats to victims seeing that the use of head protective gadgets are uncommon.

Commercial motorcycle operations were also associated with increasing robbery incidence within Lagos (Fajan, 2013). Other common deviant attitude observed among operators include rioting, excessive road rage, moreover their operation amplified local air pollution complicated traffic management problems.

Asekhame and Oisamoje (2013) argues that the restriction of commercial motorcyclist to Lagos back streets has reduced operator's income. Olusola (2013) further noted this has increased tension in their home as they find it difficult to cater 
for social needs and responsibilities. Kuforiji (2013) asserted that there may have been a relative reduction in the number of accidents and injury resulting from motorcycle operation as well as "Okada" related crime within the state following the implementation of the policy. Without any doubt issues relating to regulating commercial motorcycle operations in Lagos remain sensitive and such assessment of the policy must be empirically deduced. Questions that pertinent to clarify include by what measure has the policy affected the income stream of riders? Has incidence of "Okada" robbery improved? Does the post policy data trend indicate any safety improvement on accident and safety of commercial motorcycle operations?

In light of these, this article attempts an empirical investigation of the motorcycle restriction policy of the Lagos State Government put in place in October 2012 on the security and safety within its metropolitan Area.

\section{Aim and Objectives}

The following objectives are outlined for the study;

1.To examine the impact of Lagos restriction policy on socio-economic status of operators.

2.To examine the effect of restriction policy on crime in the study area.

3.To assess the impact of the policy on public health and safety in the study area.

\section{Methodology \\ Research Design}

The primary source of information used in the study emanated from a survey on commercial motorcyclist currently operating within Ikeja, the state capital a Local Government Area made up of 10 wards. Structured questionnaire was designed to gather information on socioeconomic characteristics, safety awareness as well as other related information bothering on the impact of the restriction policy by Lagos State Government on commercial motorcycle operation. Five personnel were recruited for the survey each to administer survey questionnaire in 2 ward areas. Other mandates include key observation of rider's attitude and behaviour. This study also sourced information from a federal medical facility. A five year monthly data for motorcycle related accident admissions at the National Orthopedic Hospital in Igbobi, Lagos was obtained. The state teaching hospital LASUTH data is ignored, as the federal facility is regarded as neutral and indifferent to politics within the state. Moreover the federal facility is a recipient of the most seriously injured persons with wards dedicated solely to motorcycle injuries.

\section{Sources of Data}

Data used in this study emanated from both primary and secondary sources. The primary information for this research was sourced through the use of structured questionnaire, personal observation and interviews on commercial motorcycle operators and law enforcement agents in the study area. Secondary data emanated from published and unpublished sources that had been previously processed and stored from sources such as government records, hospital records, internet, journals, books etc.

\section{Population and Sample Size}

The populations of the study are commercial motorcyclists currently operating various back street roads in Ikeja area with population according to Oni et al. (2012) was put at 1,500 as at year 2005. Although their number is known to have swelled significantly in subsequent years, their current population observed to have dwindled significantly a bench mark of 1,500 was however adopted as population of commercial motorcycle operators within the area. A target sample size of 120 was set for the survey in Ikeja making about of 
$8 \%$ of the total estimated population of operators.

\section{Sampling Technique}

Twelve respondents were drawn from motorcyclist operating within each of the ten ward areas that make up the Local Government Area. Random systematic sampling technique was adopted in the selection of respondents at each ward area, just as streets within each ward were also randomly selected. The random systematic process involved the throw of a die with an interval of 8 respondents representing cyclist arrivals at such park was used in selecting respondents. The rationale for choosing this technique is that it gives all riders the equal opportunity of being selected in the survey. The total of 140 questionnaires were targeted and administered to the commercial motorcyclists for which the best 120 returned were utilized for this work.

\section{Data Analysis}

Both descriptive and inferential statistics method were used in the presentation and analysis of the data obtained in the course of this research. The descriptive statistical tools used here in presenting the data include the bar chart, tables and pie chart. The inferential statistical tool employed is the Time Series Analysis and Quadratic regression model using scattered plot. Both method were used to analyse the secondary data which represent monthly hospital admission cases of motorcycle related accidents from the Orthopedic Hospital, Igbobi, Lagos. The seasonal decomposition function of time series was useful in extracting the trendcircle component of the 5 year monthly data series from hospital record. The trend circle data extraction was further used in a scatter plot from which trend analysis and a 5 month prediction of admission cases was made into 2015.
Result and Discussion

Socio-Economic Characteristics of Respondents

Table 1: Age Distribution of Respondents

\begin{tabular}{lll}
\hline Age $($ yrs $)$ & Frequency & Percentage $(\%)$ \\
\hline Less than 19 & 3 & 2.5 \\
$20-39$ & 87 & 72.5 \\
$40-59$ & 30 & 25 \\
60 yrs and above & 0 & 0 \\
Total & 120 & 100 \\
\hline
\end{tabular}

From table 1 above, majority (75\%) of respondents were between the age range of 20-39 years making it the dominant age group among operators. This service has been noted to be most attractive to young individuals as noted by Ogunrinola, (2011). Onifade, et. al., (2011) further associated the youth dominance with effort to raise start-up capital for other businesses.

Table 2: House Hold Size of Respondent

\begin{tabular}{lll}
\hline Family Size & Frequency & Percentage $(\%)$ \\
\hline Less than 3 & 24 & 20 \\
$3-5$ & 84 & 70 \\
$5-8$ & 9 & 7.5 \\
9 and above & 3 & 2.5 \\
Total & 120 & 100 \\
\hline
\end{tabular}

Most of the respondents belong to a small household unit with over $66.6 \%$ belong to a house hold size varying between 3-5 members as indicated in table 2 above.

Table 3: Have You Ever Been Involved In an Accident While Riding

\begin{tabular}{lcl}
\hline $\begin{array}{l}\text { Accident } \\
\text { involvement }\end{array}$ & Frequency & Percentage (\%) \\
\hline Yes & 119 & 92.5 \\
No & 9 & 7.5 \\
Total & 120 & 100 \\
\hline Table 3 above indicates 92.5\% of \\
respondents claim to have been involved in \\
an accident during operation, implying \\
accident is a common experience among \\
riders.
\end{tabular}




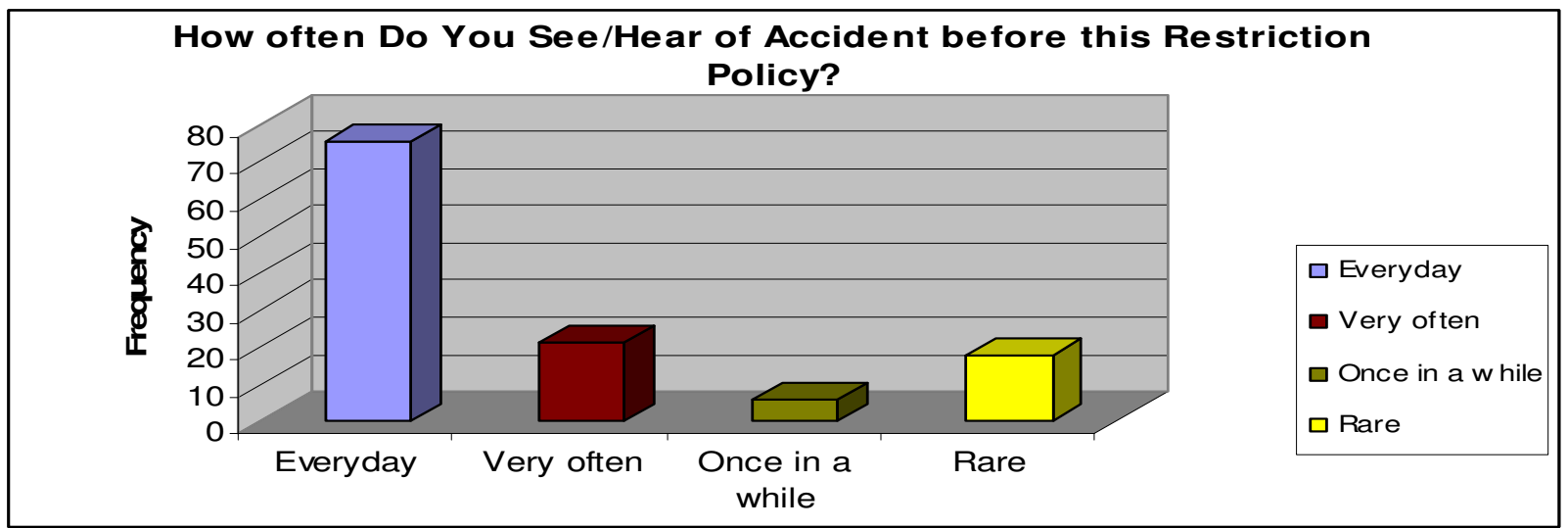

Figure 1: Opinion on level of Motorcycle accidents Prior to Restriction Policy

In figure 1 , over $83 \%$ of respondents indicated news of accident being very common before the new law. This attest to the position of most literature on motorcycle operation on the unbridled accidents associated with commercial motorcycle operation within and outside Nigeria (Mburza and Umar, 2008; Kudebong et al., 2011; Tijani, 2013; Asekhame and Oisamoje, 2013; Dinye, (2013).

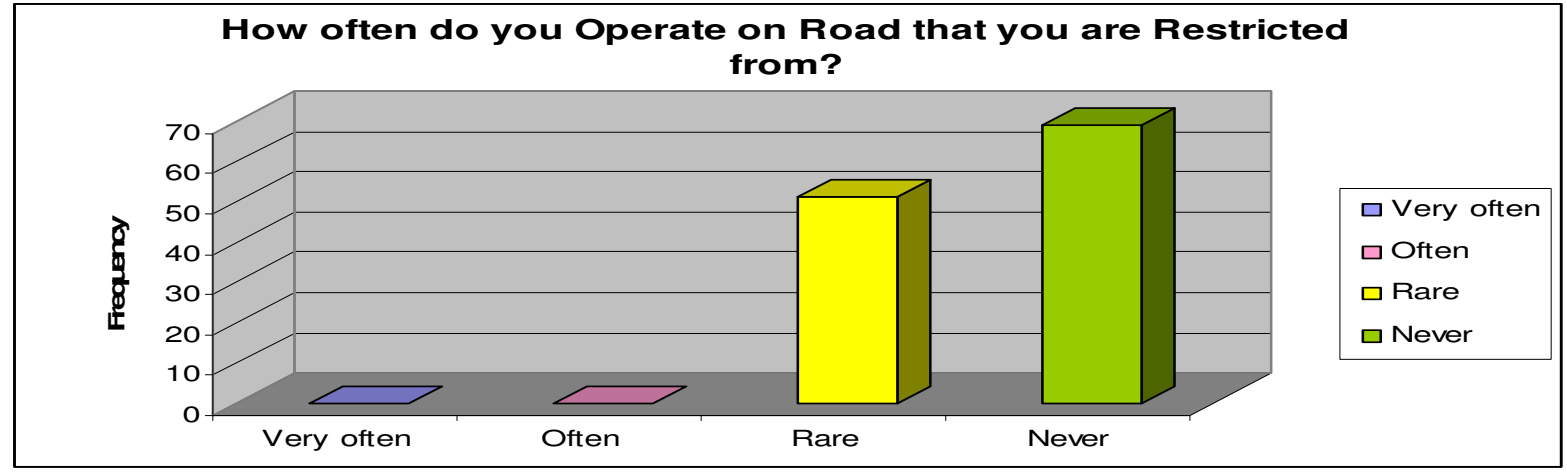

Figure 2: Opinion on Compliance with the Motorcycle Restriction Policy

The restriction policy in the state appears to have a firm enforcement footing as response of commercial motorcyclist in the study area indicates a high level of compliance to their restriction to the back streets of Lagos as indicated their response in figure 2 above.

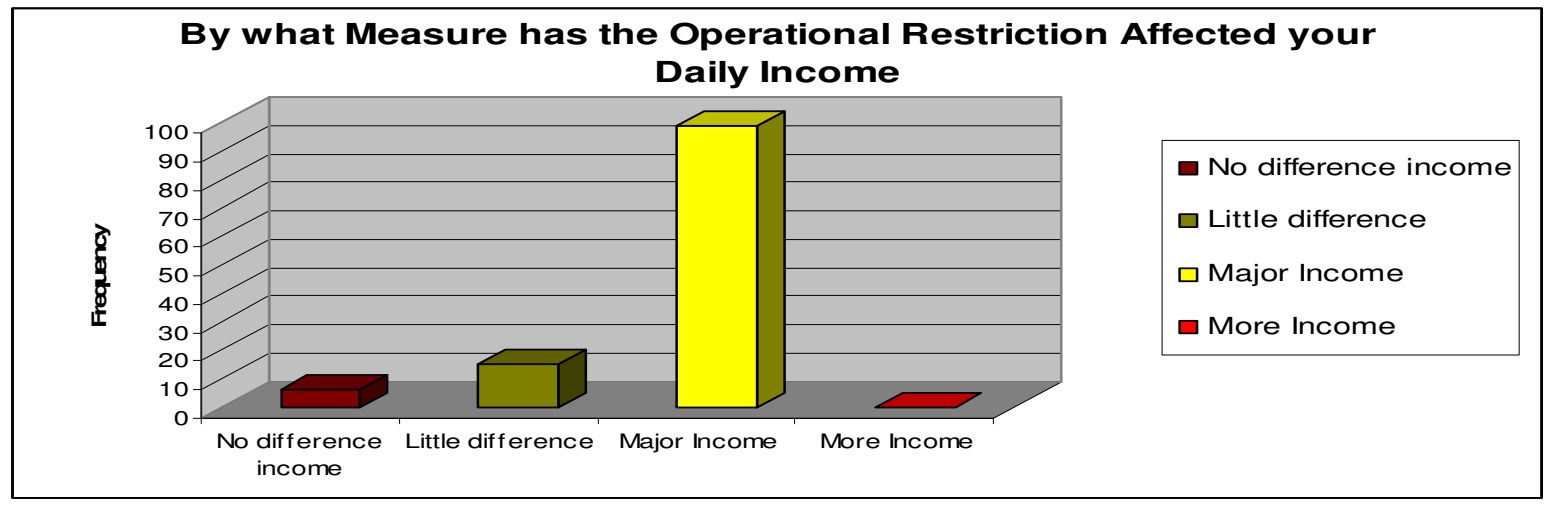

Figure 3: Opinion on Effect of Restriction Policy on Income of Operators 
As expected, the restriction of commercial motorcycle operation dealt a heavy blow to the income stream of operators. This further corroborate position of Asekhame and Oisamoje, (2013) and Olusola, (2013) who both argued that the restriction of commercial motorcyclist has significantly affected operator's income generally.

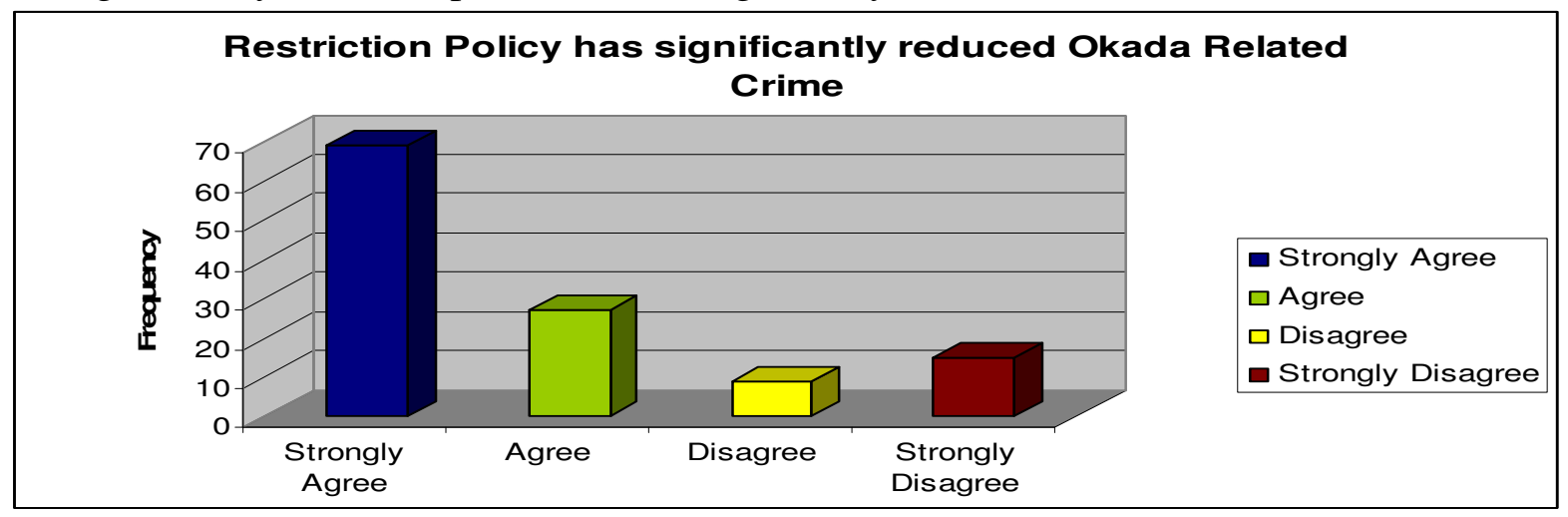

Figure 4: Opinion on Effect of Restriction Policy on Motorcycle Related Crime

Response in figure 4 above shows $85.8 \%$ of the respondents agree the policy has significantly reduced "Okada" related crime in the state as only a small percentage $(13.8 \%)$ thought otherwise. This goes further to support government position as postulated by Kuforiji, (2013) who observed the policy has indeed had a positive statewide impact on crime incidence.

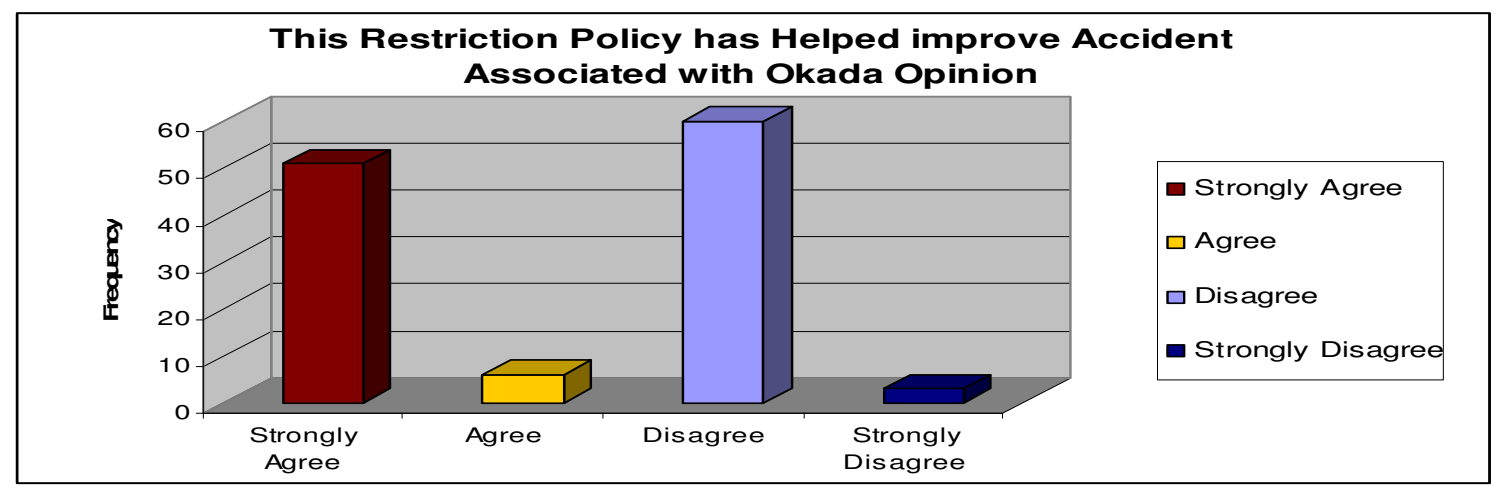

Figure 5: Opinion on the Effect of Restriction Policy on Motorcycle Accident

It is however interesting to note in figure 5 above that there is no clear consensus on the effect of the policy on motorcycle accident and safety. 52\% disagreed that nothing has changed while the remaining $48 \%$ thought otherwise. The secondary data obtained will provide the clearest unbiased information. 


\section{Analysis of Secondary Data}

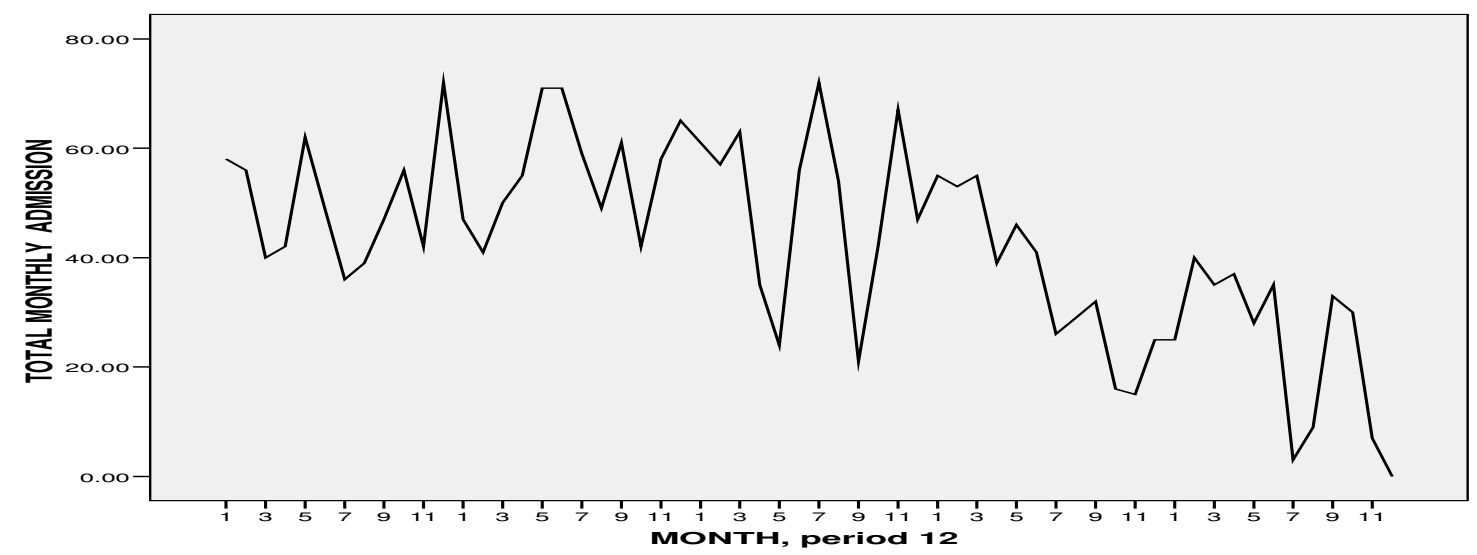

gure 6: Showing: 5 Year Monthly Pattern of Admission for Motorcycle Accident at Orthopedic Hospital Lagos.

The data series used in this section is the total monthly motorcycle accident related admissions into the National Orthopedic Hospital in Igbobi, Lagos. The data available spans a 5 year period from year 2009 (3 years before the motorcycle restriction policy of Lagos State Government and 2 years after) to 2014. A visual look at the series shows a very gentle increase in the data trend between
2009-2012. This increasing trend is however shielded by the high variance exhibited by the data set represented by the array of sharp peaks within the period. However, from year 2012 the decrease in the trend of the data becomes easily discernable. The variation appears to have reduced as there are fewer sharp spikes within the time frame under consideration.

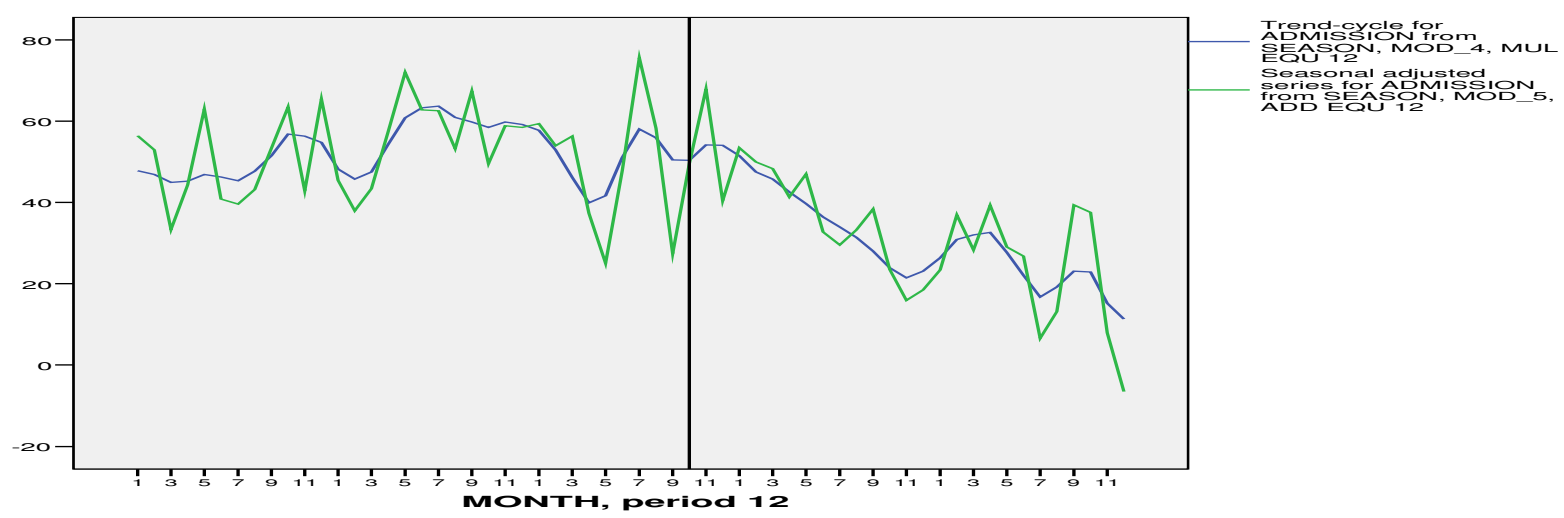

Figure 7: Showing: Seasonal Adjusted Series and Trend Cycle with Policy Intervention Date

Figure 7 above shows the plot of the seasonal adjusted series and the trend-cycle with a line indicating the inception date of the motorcycle restriction policy. The trend-cycle is a smoothened version of the original series provides the general outlook of the data trend in time, this forms the basis of further analysis and prediction. 


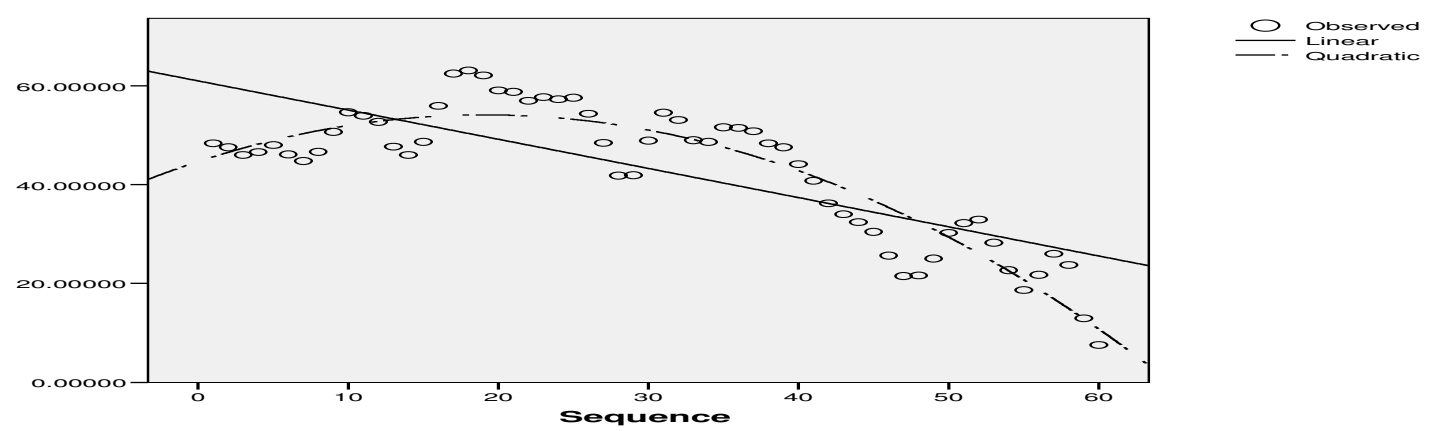

Figure 8: Scattered Plot with Linear and quadratic Fit lines for Motorcycle Accident Admission at the Orthopedic Hospital, Lagos.

To determine the effect of motorcycle restriction policy on public health, an analysis of the trend cycle pattern is examined in a scattered plot presented in figure 8 above. Two important equations to model the data series considered are the linear and quadratic fit. The formula for a the linear equation is given as;

$$
y=a+b x .
$$

where $\mathrm{Y}$ represents the number of monthly motorcycle admissions cases in the Orthopedic hospital and $\mathrm{X}$ is a time series with a 12 month cycle that spans a five year period. $a$ is the intercept of the slope on the $\mathrm{Y}$ axis while $\mathrm{b}$ is the coefficient of the slope.

On the other hand, the general formula for the quadratic curve is given as;

$$
y=c+b x+a x^{2}
$$

where $Y$ represents the number of monthly admission cases in the hospital, $\mathrm{c}$ is the interception of the slope on $\mathrm{Y}$ axis, b and a are the coefficient of the linear and quadratic function of quadratic curve.

Table 4: Model Summary and Parameter Estimates

\begin{tabular}{lllllllll}
\hline Equation & \multicolumn{2}{l}{ Model Summary } & & \multicolumn{4}{c}{ Parameter Estimates } \\
& $\mathrm{R}$ Square & $\mathrm{F}$ & $\mathrm{df} 1$ & $\mathrm{df} 2$ & Sig. & Constant & $\mathrm{b} 1$ & $\mathrm{~b} 2$ \\
Linear & .580 & 79.984 & 1 & 58 & .000 & 61.002 & -.590 & \\
Quadratic & .847 & 158.033 & 2 & 57 & .000 & 44.672 & .990 & -.026 \\
\hline
\end{tabular}

From table 4 above, the coefficient of determination $\mathrm{R}^{2}$ which indicates how well the trend line fits the scattered plot for linear fit indicates a value .580 implying the model can only account for about 58\% of the variation in the plot. Conversely the quadratic model has a coefficient of determination of .847 thus accounting for $84.7 \%$ of the variation in the data trend, hence more accurate output.

The linear and quadratic terms are two important components for analysis when using the quadratic model. When the quadratic term is negative, the linear and quadratic term compete with each other in opposing direction with the quadratic term exerting a downward force on the equation. The value of $b /-a$ thus represents the location where the downward effect of the quadratic term perfectly cancels out the upward effect of the linear term. The relationship of the maximum data value to the ratios $-b / 2 a$ and $-b / a$ are critical for understanding the shape of the curve. $b / 2 a$ represents the point at which the quadratic equation levels off, this represents the maximum possible point of the curve in this case the peak hospital admission in the series under review. 
In our plot the ratio of $b / 2 a$ is 19.04 , which means the peak of the curve in this plot falls on the 19th month with estimate admission of 57 cases. However, the actual maximum is observed to have shifted slightly further into month 21 st month, this makes the maximum point to lie between $\mathrm{b} / 2 \mathrm{a}$ and $\mathrm{b} / \mathrm{a}$. At this point the curve has reached its peak and has thus starting to decline. It is interesting to note that the downward pull by the quadratic equation has its effect at b/a, 38.08 or at the $38^{\text {th }}$ month of the series( 3 years and 2 months) which incidentally is the point of introduction of the motorcycle restriction policy in Lagos State. It is from this point the quadratic term in the equation begins to deflect the series downwards after it had leveled off.
The 8 month difference between the exact effective date /enforcement of the law and the pull of the quadratic equation may as well be due to the effect of earlier effort to enforce motorcycle safety regulations and initial restriction from cyclist from the state highway network or just a random deflection in the trend cycle of the original series. In other words we conclude that the downward trend exhibited by the orthopedic hospital admission data from the 38th month is as a result of the policy of the state to restrict "Okada" operation since the linear component of the quadratic term $(0.99)$ is a sharp increasing trend that was cancelled out at the point of implementation of the restriction policy of the government of Lagos State.

Table 5: Showing: Forecast for Motorcycle Admission at Orthopedic Hospital

\begin{tabular}{llllll}
\hline Month (2015) & Jan & Feb & Mar & Apr & May \\
\hline No of admission cases & 8.3 & 6.1 & 3.8 & 1.5 & -0.8 \\
\hline
\end{tabular}

A five month forecast into year 2015 using the quadratic regression model also indicates a decreasing trend in the number of cases emanating from "Okada" related accidents at the orthopedic hospital, Igbobi. Within the first four months of 2015 , admission cases is expected to fall from 8 cases in the month of January to a little over a single case in April. By June 2015 there will be no case of admission from motorcycle accident at the facility.

\section{Conclusion}

Empirical analysis of motorcycle accident admission cases suggest that enforcement of the restriction policy adopted by Lagos state government is impacting positively on safety with a continuous reduction in the trend of such accidents within Lagos Metropolis. The survey also suggest motorcycle related crime has significantly been reduced. This study thus concludes that the motorcycle restriction policy which came into force in October 2012 has had a far reaching positive effect on the general wellbeing of inhabitants of the state as its roads are today more serene than what was obtainable prior to the ban in October 2012. Other studies especially such that will focus on the impact of the policy on commuter's mobility and adaptation is indeed desirable.

\section{Recommendation}

In view of the outcome this research the study makes the following recommendations;

The Lagos State Government must be unrelenting in the enforcement of the motorcycle restriction so as to avoid a relapse in compliance to the law.

Adequate enforcement on regulations should be implemented particularly 
measures to ensure good safety practice among existing commercial cyclist now operating on metropolitan back street.

Government of Lagos State should ensure other economic empowerment programmes are accessible to individuals who wish to transit from the business as a way of handling the possible negative effects of the policy.

\section{Reference}

Adeyeye, S.O. (2011). The motorcycle crash characteristics in Lagos state, Nigeria. Journal of Environmental Management and Safety, 2(1): 1-15.

Asekhame, F.F. and Oisamoje, M.D. (2013). Ban on commercial motorcycle operations in Benin City, Nigeria: an appraisal of the benefits and business opportunities. Journal of Developing Country Studies, 3(14): 10-17.

Badejo, B.A. (2011). The transportation realities challenges and opportunities of Lagos State. A 50th Anniversary Lecture University of Ibadan.

Bamidele, A.C. (2012). Predictors of road traffic injury and death among commercial motorcyclists in an urban area of Nigeria. Nigeria Journal of Medicine. 18(4): 393-397.

Boye, S.R. (2013). Saving lives in our roads: A shared responsibility. Lux Embourg. Office for the Official Publication of the European Communities.

Dinye, R.D. (2013). The significance and issues of motorcycle transport in the Urban areas in northern Ghana. Scientific Journal of Review, 2(10): 256-272. doi:10.14196/sjas.v2i10.1032

Eze, C.U., Abonyi, L.C., Ohagwu, C.C. and Eze, J.C. (2013). Pattern of plain $\mathrm{x}$-ray findings in bone injuries among motorcycle accident victims in
Lagos, Nigeria. International Research Journal of Medicine and Medical Sciences, 1(2): 51-55.

Fajan, O.O. (2013). Can road traffic law enforcement permanently reduce the number of accidents. In Proceedings of Road Safety and Traffic Environment in Europe, Gothenburg, Sweden, September, 26-28, 1013,2013 VTI Rapports, 365A 122 145.

Kudebong, M.F., Wurapa, F., Nonvignon, J., Norman, I., Awoonor-Williams, J.K. and Aikins M. (2011). Economic burden of motorcycle accidents in Northern Ghana. Ghana Medical Journal, 45(4): 135-142.

Kuforiji, O.O. (2013). Commercial motorcycles and number plate in Lagos State. A preliminary Investigation. Journal of Logistic and Transport, 1(1): 96-104

Mburza, A. and Umar, N.B. (2008). Causes of accidents among commercial motorcyclists ("Okada") in Borno State: Implications for Counseling. Nigerian Journal of Guidance and Counselling, 13(1): 171-179.

National Highway Traffic Safety Administration (NHTSA) (2004). Report on motorcycle helmet Effectiveness revisited. wwwnrd.nhtsa.dot.gov/pubs/809715.

Ogunmodede, T., Ayinla, A.G., Ebijuwa, A.S., Oyetola, S.O. and Akinola, J.O. (2012). Factors influencing high rate of commercial motorcycle accidents in Nigeria. American International Journal of Contemporary Research, 2(1): 130-140.

Ogunrinola, O.I. (2011). Global economic crisis and career aspirations among 'okada' riders in Nigeria: the influence of apprenticeship skills 
training. Business and Economics Research Journal, 2(3): 51-67.

Olagunju, K. (2001). The "Okada" menace on Nigeria road. National Interest, 1(237): $15-18$

Olusanya, E.O. (2011). Effect of safety education on knowledge of and compliance with road safety among commercial motorcyclists in Uyo, Southern Nigeria. Ghana Medical Journal, 45(3): 89-96.

Olusola, B.G (2013). "Effect of road Lightning :An Analysis Based on Dutch Accident Statistics 1987-2006. Accident Analysis and Prevention, 41(i): 123-128.

Oni S.I., Fashina O. and Olagunju Y.K. (2011). The motorcycle crash characteristics in Lagos State, Nigeria. Journal of Environmental Management and Safety, 2(1): 1 - 15.
Onifade, C.A., Aduradola, R.R. and Amao, S.O. (2012). The Effect of SocioEconomic Survival of Okada Riders on African Cultural Values. Journal of Human Social Science, Arts and Humanities, 12(14): 45-52.

Oyesiku, O.O. (2002). From womb to tomb 24th inaugural lecture, Olabisi Onabanjo University. Ago Iwoye: (OOU) Press pp 93-98.

Tijani, T.B. (2013). Trends in motorcycle accident in Lokoja, Nigeria. European International Journal of Science and Technology, 2(6): 251261.

World Health Organization (2004). Report on global status report on road safety time for action. www.un.org/ar/roadsafety/pdf/roadsa fetyreport. 